\title{
"Nossos filhos não são cobaias": objetificação dos sujeitos de pesquisa e saturação do campo durante a epidemia de Zika
}

\author{
"Nossos filhos não são cobaias": Objectification of Subjects and Field \\ Saturation: effects of the Zika epidemic
}

\author{
Luciana Lira ${ }^{1}$ \\ Helena Prado ${ }^{2}$ \\ ${ }^{1}$ Faculdade Damas - FADIC, Recife, PE, Brasil \\ ${ }^{2}$ Université de Strasbourg, Strasbourg, Alsace, França
}


“Nossos filhos não são cobaias": objetificação dos sujeitos de pesquisa e saturação do campo...

\section{Resumo}

Decidimos escrever este artigo a quatro mãos por uma razão simples: apresentar dois lados da mesma história, a história dos desdobramentos da pesquisa durante a epidemia de Zika. Nesse sentido, não somente expomos duas experiências como pesquisadoras em antropologia sobre a epidemia do vírus Zika, mas propomos mostrar como essas duas experiências e vivências revelam de alguma forma um sistema complexo atuando nesse contexto específico e envolvendo descobertas científicas, financiamentos internacionais, concorrência de pesquisadores e de instituições, campo com mulheres, crianças vulneráveis e instituições de saúde, trajetórias de amostras biológicas, colaborações - às vezes, assimétricas - entre científicos dos chamados 'Sul e Norte' do mundo. Esperamos, dessa forma, chegar a um retrato da Science in the making que proporcionará uma reflexividade a diferentes níveis sobre: 1) nossas práticas como pesquisadores em antropologia em tempos de crise e emergência e 2) os diversos significados da relação centro-periferia/ pesquisador-pessoas no campo nas ciências que tratam da saúde.

Palavras-chave: Pesquisa. Síndrome Congênita do Zika. Objetificação.

\section{Abstract}

We decided to write this article in four hands for one simple reason: to present two sides of the same story, a story of research during the Zika epidemic. To that extent, not only do we expose two experiences as researchers in anthropology about the Zika virus epidemic, but we aim to point out how these two experiences and feelings reveal in some way a system activated through this specific context that interlocks scientific discoveries, international funding, competition of scholars and institutions, ethnographic field with women, vulnerable children and health institutions, trajectories of biological materials, collaborations sometimes asymmetric - between the 'South and North' of the world. In doing so we hope to reveal a portrait of science in the making. We propose to reflect on two different levels: 1) our practices as researchers in anthropology in times of crisis and emergency, and 2) the various meanings of the center-periphery/researcher-fieldwork participants relationships in the social study of health.

Keywords: Research. Congenital Syndrome of Zika. Objectification. 


\section{Introdução}

ecidimos escrever esse artigo a quatro mãos por uma razão simples: apresentar dois lados da mesma história, a história dos desdobramentos da pesquisa durante a epidemia de Zika.

Nesse sentido, não somente expomos duas experiências como pesquisadoras em antropologia sobre a epidemia do vírus Zika, mas propomos mostrar como essas duas experiências e vivências revelam de alguma forma um sistema complexo atuando neste contexto específico e envolvendo descobertas científicas, financiamentos internacionais, concorrência de pesquisadores e de instituições, campo com mulheres, crianças vulneráveis e instituições de saúde, trajetórias de amostras biológicas, colaborações - às vezes, assimétricas - entre científicos dos chamados 'Sul e Norte' do mundo. Esperamos, dessa forma, chegar a um retrato da Science in the making que proporcionará uma reflexividade a diferentes níveis sobre: 1) nossas práticas como pesquisadores em antropologia em tempos de crise e emergência e 2) os diversos significados da relação centro-periferia/pesquisador-pessoas no campo nas ciências que tratam da saúde. Atravessando assim pontos metodológicos, epistemológicos e éticos envolvendo questões de violência do campo, de objetificação dos sujeitos de pesquisa (mães e crianças), pontos cegos e impasses, e de legitimidade da coleta de dados, temos por âmbito responder à questão fundamental dos antropólogos: como produzimos conhecimento e o quê e para quem produzimos?

Tomaremos como ponto de partida o início de pesquisa de cada uma de nós, uma no Recife, outra em Paris. Uma iniciando a pesquisa como sujeito e antropóloga logo no foco da epidemia, outra despertando interesse por meio da cobertura midiática da epidemia de Zika no 
outro lado do mundo - e mais tarde a respeito da microcefalia entre os recém-nascidos. Por essa razão, este artigo apresentará diferentes estilos ao longo do texto, relatos individuais de reflexões e anotações de caderno de campo, seguidos de uma síntese das reflexões geradas por essas experiências.

\section{Síndrome Congênita do Zika: um campo habitado por pesquisa}

\section{Helena}

Paris, 2016

Há alguns tempos tenho me interessado pela questão das normas e práticas de saúde materna no Brasil, e sobretudo por uma de suas especificidades no mundo: a alta taxa de cesárea e de partos biomedicalizados em ambos os setores públicos e privados. Em meio às questões e leituras sobre medicalização do parto, monitoramento da gravidez, representações do corpo da gestante e do feto no Brasil, deparo-me um dia de janeiro com imagens exóticas na TV francesa. Após meses mostrando a expansão de um mosquito sanguinário pelo mundo ${ }^{1}$, o famoso mosquito-tigre (Aedes albopictus, mas na verdade o responsável é o Aedes aegypti), e sua ligação com a disseminação de uma nova ameaça chamada "Zika" na América do Sul, digna irmã dos vírus da Dengue e do Chikungunya, surgem novas imagens espetaculares e dramáticas: as de dezenas de bebês nascidos com microcefalia, uma malformação severa e frequentemente visível da cabeça do recémnascido.

Animada pelo desejo de observar e entender in situ o que está acontecendo, mas também orientada pelo efeito trágico e extraordinário que muitas vezes move os antropólogos quando escolhem um campo de pesquisa - com razão ou não -, desenvolvo um projeto de pesquisa em seguida. Dias após a declaração da Organização Mundial da Saúde de Public Health Emergency of International Concern (WHO, 2016), colocando o vírus Zika como prioridade de investigação necessitando monitoramento internacional e vigilância sanitária -, que ocorre após a confirmação da relação entre infecção de mulheres grávidas pelo vírus Zika e malformações congênitas como a microcefalia, meu projeto é 
enviado para solicitação de financiamento a um organismo público de pesquisa na França ${ }^{2}$. O objetivo primeiro do projeto é entender a relação entre as diferentes instituições de governança (global, nacional, local) e a incidência de suas políticas sobre as práticas locais dos profissionais de saúde e as pessoas afetadas e vulneráveis. Em particular, o projeto focaliza-se sobre o uso das tecnologias de diagnóstico, de monitoramento e de controle da reprodução utilizadas segundo protocolos estabelecidos, ou ainda subvertidas e/ou ilegais. Nove meses depois, ao receber a excelente notícia de que obtive um financiamento de dois anos, início a preparação da pesquisa de campo.

Durante os meses a seguir, dedico meu tempo à revista de literatura e atualização das últimas descobertas biomédicas em relação à disseminação, à transmissão, à epidemiologia, aos efeitos do vírus Zika. Cada dia há uma novidade, cada dia há novas publicações científicas nas mais prestigiosas revistas internacionais de ciências médicas, cada dia há uma nova reportagem na TV ou na imprensa. Começa então um processo de delimitação do sujeito da pesquisa, e conforme o tempo passa, tudo me leva a crer que o momento não está mais para observação do uso de técnicas de diagnóstico, monitoramento ou controle em torno de mulheres grávidas ou que estão para engravidar. O foco da crise sanitária no Brasil se deslocou para a questão das mães de crianças que já nasceram, e foram diagnosticadas com malformação congênita como a microcefalia. Naquela hora - e até hoje - a tragédia da epidemia é esta: como cuidar, quem cuida, com que recursos, com que amparo, dessas crianças cuja síndrome é ainda mal diagnosticada e desconhecida?

Visto de Paris, onde converso com colegas de ciências sociais, especialistas de questões de desenvolvimento nos chamados "países do Sul" (a maioria na África Subsaariana ou na Ásia), a ideia de reorientar minha pesquisa para as mães parece relevante e inédita no cenário acadêmico francês. Embora muitos, no centro de pesquisa em que estou, tenham como temática predileta a saúde sexual e materna em contextos geográficos e culturais diversos, a possibilidade de investigar um campo em estado de emergência (ainda mais trágico e extraordinário do que inicialmente), aparece certamente como uma 
"mais-valia", tanto do ponto de vista empírico de intenção de melhor compreensão do fenômeno biossocial, como no "mercado" institucional das pesquisas (financiamentos, parcerias, publicações, comunicações) que traz reconhecimento internacional, prestígio e recursos. A memória da crise sanitária do vírus Ebola na África em 2014 ainda está presente, e com ela as controvérsias científicas em torno da gestão sanitária mundial, os conflitos entre as governanças globais, nacionais, e locais, os antropólogos dos países do norte chamados com urgência para intervir junto da população cujos ritos funerários "tradicionais" interferem com as recomendações médicas ${ }^{3}[\ldots]$ e milhares de publicações a respeito dos aspectos médicos, econômicos, sociais e culturais (ABRAMOWITZ, 2017). A epidemia de Zika aparece então como uma possibilidade de comparar as políticas de saúde e práticas de gestão de populações vulneráveis num cenário de emergência.

\section{Luciana}

Recife, 2016

A partir da segunda metade de 2015 um aumento significativo no número de casos de crianças nascidas com microcefalia e outras alterações neurológicas e motoras chamou atenção dos especialistas em Pernambuco e outros estados do Brasil, especialmente na região nordeste, gerando grande comoção na comunidade acadêmica e nas instituições de saúde, tanto públicas quanto privadas. Recursos humanos e tecnológicos importantes foram alocados para desvendar aquele que se tornaria um dos problemas de saúde pública mais noticiados no país nas últimas décadas. Sobre esse investimento Silva, Matos e Quadros (2017, p. 226) afirmam:

[...] se forma um mercado em que o Estado brasileiro passa a ser provedor e consumidor, gerando demandas como a criação de novas vacinas, kits para detecção sorológica, financiamento de pesquisas e capacitação de profissionais. No discurso do Estado, observa-se ênfase na busca por novas tecnologias para controle do mosquito, engajamento, mobilização social e o fortalecimento de ações integradas, mas pouco tem sido feito para apoiar as famílias de crianças com SCZ, principalmente os/as cuidadores/as. 
Para entender e atuar no contexto dessa nova emergência epidemiológica, uma rede de pesquisadores e profissionais de saúde de diferentes especialidades se constituiu em caráter também emergencial, com capacidade para fornecer importantes chaves de compreensão do fenômeno, como a constatação de que o surto de microcefalia estava associado à contaminação da mulher durante o período gestacional pelo vírus Zika, transmitido pelo mosquito Aedes Aegypti (MLAKAR et al., 2016). A descoberta ocorreu ainda em novembro de 2015 e, a partir dessas constatações, o Ministério da Saúde decretou estado de emergência de saúde pública nacional em dezembro do mesmo ano. Naquele momento, vários ministérios integraram uma política intersetorial para enfrentar a epidemia, incluindo a atenção às crianças e famílias afetadas pelo vírus (LIRA; SCOTT; MEIRA, 2017).

Diferentes grupos de pesquisadores, desde profissionais médicos que atendiam essas mulheres e seus filhos em seus consultórios e nos hospitais, bem como pesquisadores mais distantes da prática clínica e assistencial, passaram a integrar equipes, núcleos de pesquisa ou ainda realizar pesquisas individuais para melhor compreender e intervir sobre a epidemia. Além disso, toda essa movimentação no campo médico/ científico foi acompanhada e, diversas vezes, promovida pela gestão pública em saúde no âmbito nacional e estadual, com forte atuação de seus segmentos específicos. O papel da pesquisa nacional em ciência biomédica foi fundamental para dar visibilidade ao Brasil em relação à mobilização mundial em torno de Zika ${ }^{4}$. Lembramos também das prestigiosas revistas Nature (2016) e Time (2017) que homenagearam a Doutora Celina Turchi, especialista em doenças infeciosas da Fiocruz Pernambuco, como uma das maiores personalidades e cientistas do ano, por ter provado a relação entre o vírus Zika e a microcefalia; e ainda a Doutora Patrícia Brasil, pela pesquisa sobre Zika e grávidas. Além do sucesso e da visibilidade de personalidades científicas brasileiras, criou-se também espaço para uma rede fundamental de colaborações internacionais (MAIA et al., 2019).

De uma forma muito específica, assistência à saúde e pesquisa caminharam juntas desde o início da crise, sendo o tratamento ofertado condição para a pesquisa e vice-versa, nos mutirões de consulta e 
exames, no cotidiano dos consultórios e nas terapias, profissionais de saúde realizam atendimento e pesquisa de forma concomitante. Essa relação à reciprocidade e interdependência entre pesquisa, vigilância em saúde e atenção à saúde se justificam tendo em vista o interesse produzido num contexto de crise em saúde pública, como é o caso de um quadro epidêmico considerado risco à saúde global, que se alinha às pressões da globalização para assegurar a saúde como bem público global (DAS, 2016).

Naquele ano de 2016 e nos anos seguintes, uma quantidade considerável de recursos foram alocados para pesquisas de diferentes campos, incluindo as ciências sociais, e com diferentes objetivos e temas para dar conta da realidade que se instaurara. Inicio meu trabalho de campo como parte do pós-doutorado no fim de 2016, na “Etnografando Cuidados e Pensando Políticas Públicas e gestão de Serviços de Saúde para Mulheres e Seus Filhos com Distúrbios Neurológicos Relacionados com Zika em Pernambuco, Brasil" ${ }^{5}$. A pesquisa responde ao edital do DECIT do Ministério da Saúde para o Combate ao Zika, que financiou, além desse, cerca de 70 projetos de pesquisa de diferentes áreas. Também temos o aporte, a partir de uma parceria interinstitucional, com o Projeto "Action Ethnography on Care, Disability and Health Policy and Administration of Public Service for Women and Caretakers of Zika vírus affected Children in Pernambuco, Brazil" ${ }^{\prime 6}$ com financiamento internacional.

Acesso o campo após algumas conversas com pesquisadores de outros grupos e instituições, e com profissionais e funcionários da burocracia das instituições de saúde, responsáveis pelos processos permissivos para realização da pesquisa em seus ambientes. Desde esse momento uma narrativa preponderava sobre a saturação do campo, no sentido de que essas mulheres já não aguentavam mais pesquisadores (LIRA; SCOTT; MEIRA, 2017). Concomitante a essas conversas iniciais, ainda em dezembro de 2016, em visitas à sede de uma das associações, essa formada por mães de crianças com Síndrome raras $^{7}$ - que incluía mães de crianças com Síndrome Congênita do Zika Vírus - tenho meus primeiros contatos com as mães. As relações se estendem a outros espaços: circulando nos centros de atendimento, 
nos eventos públicos, nas festividades das associações. Na segunda instituição, formada apenas pelas mães de crianças com a Síndrome Congênita do Zika Vírus, a União de Mães de Anjos (UMA), posso sentir a desconfiança e cansaço das mulheres com pesquisadores - a noção de saturação ganha corpo.

Isso obrigou-me a adequar a metodologia e o planejamento inicial da pesquisa para estender o período de convivência e garantir a formação de vínculos em campo; especialmente no intuito de não reproduzir o tipo de relação percebida por elas como relações instrumentais e pouco compromissadas, marcadas pela falta de transparência e a quase total ausência de devolutivas de pesquisas. O que aponta para uma relação desigual e interessada em ganhos pessoais, segundo essas narrativas. A adaptação metodológica da pesquisa, discutida em artigo anterior (LIRA; SCOTT; MEIRA, 2017), resultou numa diversificação das técnicas, estratégias, mas acima de tudo uma atenção voltada para os aspectos relacionais e éticos vinculados à produção do conhecimento nesse campo, marcado por desconfianças e incertezas, e também por disputas narrativas nas abordagens de pesquisadores, veículos de comunicação, gestores públicos e a própria sociedade civil ${ }^{8}$.

\section{Helena}

São Paulo, julho de 2017

Finalmente, em julho de 2017, chego em São Paulo após três anos de ausência. Ainda no Aeroporto de Guarulhos, local asséptico por excelência, deparo-me com um cartaz chamando a atenção dos viajantes para os riscos de infecção por mosquitos e epidemia de Zika.

Há um ano e meio que a epidemia foi declarada emergência internacional pela OMS (PHEIC) - entretanto, já não é mais considerada como emergência a nível global nem nacional devido à queda do número de casos. Começa, para mim, busca de contatos, profissionais de saúde, associações de pacientes, famílias afetadas pelo vírus Zika, pesquisadores em ciências sociais, biomedicina, epidemiologia, centros de vigilância sanitária, ambulatórios exclusivos para o cuidado desses pacientes etc. Logo chega o desespero, o pesadelo do investigador: no estado de São Paulo, é como se nada tivesse acontecido, a epidemia se foi e com ela, as preocupações e medidas de prevenção. Estamos no inverno, mais 
de um ano após o auge da epidemia. Entre os contatos que consigo entrevistar, a ansiedade causada pela circulação do vírus e seus efeitos iatrogênicos só é ainda palpável nas mulheres que queriam engravidar ou engravidaram durante a epidemia de Zika - mas nenhumas das que entrevistei foi afetada, nem conhecia alguém afetado. Entre os profissionais de saúde, médicos e ginecologistas, que ainda se interessam pela questão, o discurso é unânime: Zika ocorreu lá no Nordeste. Sim, mas a percepção de que havia um risco, de que o vírus Zika era um perigo a evitar, ocorreu na pele das mulheres em idade fértil do Brasil todo, do resto da América do Sul e da Europa também, ultrapassando as fronteiras epidemiológicas.

\section{Recife, setembro de 2017}

Graças a uma rede de contato entre pesquisadores, acabei por conhecer Soraya Fleischer, antropóloga, que pesquisa as "mães de micro", ou seja, as mães de crianças diagnosticadas com microcefalia decorrente da infecção, durante a gravidez, pelo vírus Zika. Combinamos de nos encontrar no Recife onde ela faz campo, para nos conhecer pessoalmente. Aproveitarei também um seminário na Universidade Federal de Pernambuco com duas antropólogas do Reino-Unido convidadas no âmbito do projeto Care in times of Zika and reproductive rights que foi contemplado com financiamentos brasileiros e britânicos.

Recife é uma cidade desconhecida para mim, bem como toda a região do Nordeste. Aplico à letra os conselhos da minha colega antropóloga com quem combinei de encontrar para visitar, junto com a equipe de pesquisa de Recife, duas associações que cuidam de crianças com microcefalia decorrente de Zika. A primeira associação cuida de crianças e adolescentes com deficiência, num bairro pobre de Recife. Pela primeira vez na vida, subo o morro de moto-táxi, e chego no local conhecido pelos habitantes do bairro por volta de 8 horas da manhã. O sol já está quente e as ruas do bairro estão animadas. $\mathrm{Na}$ entrada, um cameraman e uma jornalista estão entrevistando uma jovem mãe, que carrega um filho com microcefalia visível no colo. Ao redor todo mundo para para olhar, curioso, para as câmeras e as luzes da TV. Eu também observo curiosa, afinal de contas é a primeira vez que cheguei tão perto do sujeito de pesquisa que tantas vezes vi na 
televisão. A mãe está animada e leva os jornalistas para conhecer sua casa que fica a alguns metros dali; penso que gostaria de aproveitar a oportunidade e segui-los, ao mesmo tempo que não posso deixar de deplorar a instrumentalização pelos jornalistas de TV, obscena ao meu ver, das situações de sofrimento e aflição alheia. As crianças nascidas na época da epidemia de Zika estão completando um ano. A reportagem acontece na "data aniversário" e oferece um frágil esboço do que deve ter sido a cobertura midiática mais de um ano antes...

Entro na associação e depois de me apresentar, sou levada até a piscina de reeducação. Minha colega está já pesquisando há uma hora, observando, caderno de campo na mão, a sessão de reeducação de um bebê de Zika com a mãe ao lado. Conversamos, trocamos algumas ideias e saio novamente para esperar o resto da equipe que vai visitar o centro. A equipe chega: dois professores de Recife, duas pós-doutorandas, duas professoras visitante do Reino Unido se juntam a minha colega do sul do Brasil, e eu, da França, para um grande tour do centro, liderado por um dos responsáveis do centro, em busca de oportunidade de conhecer as mães de micro. Cada sala que visitamos tem uma atividade específica, estimulação precoce, trabalho artístico, fisioterapia. As crianças acolhidas têm idades e trajetórias muito variadas, algumas estão acompanhadas de um parente, ou de um tutor no caso de uma criança que vive num orfanato. Enquanto entramos nas diferentes salas, as professoras convidadas se dirigem para as mães com crianças com microcefalia. As outras mães, com filhos com paralisia cerebral por exemplo ou outros tipos de deficiência, ficam olhando para nós, esperando despertar nosso interesse. Estamos em um grupo grande, na sua maioria mulheres brancas, algumas estrangeiras, e não paro de pensar na imagem que estamos a dar: às vezes cruzo num olhar uma reação de felicidade, de orgulho até, pela atenção que os funcionários, as mães e os bebês estão recebendo de nossa parte. Outras vezes parece mais próximo da humildade, ou da vergonha. Me pergunto então se somos tão diferentes dos jornalistas.

Em um artigo sobre a etnografia de pacientes com AIDS no Botswana, F. Chabrol (2008, p. 230) é confrontada para a percepção da interlocutora de um hospital sobre os cientistas sociais: “[...] todo 
mundo vem nos ver aqui, até os que não têm interesse no que fazemos. Somos um parque de atração $[\ldots]^{\prime \prime}$, significando que o hospital e seus pacientes eram objetos de curiosidade, cobiçados por muitos pesquisadores presentes no mesmo campo. Esta experiência no centro de reeducação de crianças deficientes me deixa a mesma impressão. O caso da epidemia de AIDS nos ajuda a repensar esta relação entre pesquisador e sujeito de pesquisa, por ser um exemplo paradigmático de um campo saturado pelas ciências biomédicas e pelas ciências

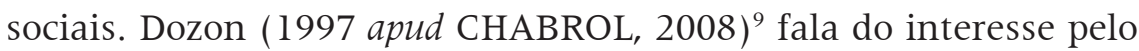
fenômeno multidimensional do ponto de vista dos antropólogos. Ocorre na epidemia de Zika em Pernambuco, o mesmo que com o cuidado de pacientes de AIDS no Botswana: suscita múltiplos interesses científicos por conjugar ao mesmo tempo a presença de um vírus específico, uma população cujas características biológicas são cobiçadas pela pesquisa biomédica internacional, uma alta taxa de prevalência que favorece a coleta de amostras, e as infraestruturas clínicas capazes de pôr em práticas pesquisas e ensaios clínicos (DOZON, 1997 apud CHABROL, 2008). De maneira óbvia, o mesmo acontece em Recife, capital do estado de Pernambuco com as crianças com Síndrome Congênita de Zika. Ao mesmo tempo que a epidemia de Zika surge como uma questão de saúde pública muito visível, que arrecada uma quantia muito grande de financiamentos, outras patologias, como as outras arboviroses e outras síndromes congênitas que causam deficiências, caem no esquecimento e são negligenciadas ${ }^{10}$ - o que se expressa no olhar das mães de filhos com outras deficiências que cruzei durante a visita.

Todas as mulheres que vi naquele dia relataram o investimento moral, afetivo e material que elas têm frente ao cuidado do filho. Cada sala visitada carregava um peso emocional. Não consegui tirar meu caderno de campo na hora, não ousei; tampouco conversei com as mães de maneira direta, fiquei ao lado do nosso guia com o qual, por ele saber quem éramos e o que estávamos fazendo, não temia o risco de objetificar. De fato, ainda mais que em outras situações comuns de pesquisa etnográfica, a relação de poder entre pesquisador e pesquisado aparecia para mim como insuperável metodologicamente e insustentável eticamente. 
Neste primeiro contato com o campo, ainda não sabia quais ajustes metodológicos escolher em resposta a esse desconforto - viria a ser uma mudança de campo, menos pesquisado e à margem, mas que foi descoberto graças a esta experiência. A minha colega Luciana, por sua vez, conseguiu construir relações de confiança estabelecidas graças a uma presença constante na etnografia com "mães de micro" dentro deste campo, mas teve que lutar contra os desafios da produção - e possessão! - de dados numa concorrência entre pesquisadores de várias regiões do Brasil, e também de outras regiões do mundo, numa sobrevivência de pós-colonialismo.

\section{Luciana}

Recife, setembro de 2017

Por volta de $8 \mathrm{~h}$ da manhã chegamos para mais uma visita a uma das instituições que oferece atendimento a crianças com deficiência em Recife - a mesma que havia visitado um mês antes na companhia de uma colega pesquisadora da equipe. Nesse momento anterior, a diretora da instituição que atende as crianças com Síndrome Congênita do Zika Vírus num bairro da periferia de Recife, narrou um pouco sobre o impacto da chegada dessas crianças para atendimento como situação extraordinária; incluiu o aporte financeiro oriundo de financiamentos internacionais (que estão na base de sustentação do trabalho filantrópico que realizam há cerca de 30 anos na localidade), e que recebeu incrementos substanciais tendo em vista a nova demanda por atendimento às crianças com SCZ. Ela fala sobre a diferença de atenção que a Síndrome recebe em detrimento de outras condições igualmente complexas, como o autismo, que, segundo Clara, aumentou vertiginosamente nos anos recentes e merecia maior empenho na elucidação.

De forma distinta, nesse dia de visita, além de mim e das outras duas pesquisadoras de campo da equipe, estavam presentes os coordenadores da pesquisa e pesquisadoras parceiras de outras instituições, importantes universidades e centros de pesquisa do Rio, de Brasília, do Reino Unido e mais uma pesquisadora que chegará há pouco da França, iniciando seu trabalho de campo em Recife, e que escreve comigo este artigo. Apesar de proveitosa e estimulante a 
ocasião da visita, todo esse aparato e atenção acende o alerta para nós do risco do caráter de "expedição" que assume a nossa visita. Enquanto conversamos com profissionais que oferecem as terapias, com as mães ali presentes que acompanham seus filhos, transitamos nos espaços terapêuticos, recreativos, conhecemos a cozinha, a pequena sala de refeições, a piscina, a oficina de artes e ouvimos as experiências do cotidiano dos serviços e relações tecidas ali. Encontro, como de costume em todas as visitas aos serviços, mães que conheço e/ou acompanho em outras situações de campo. Entre elas, Isa que acompanha sua filha Marina às terapias praticamente todos os dias da semana. Ela, sempre sorridente e extrovertida, estava logo no início da nossa visita do lado de fora da instituição repetindo sua entrada para que a equipe de TV, que gravava naquele dia seu cotidiano de cuidados com a filha, pudesse pegar a melhor performance sobre critérios definidos por essa mesma equipe. As outras mães e pacientes ali presentes, bem como os funcionários do local e moradores que ali transitavam pareciam acostumados com a situação que se apresentava. Era uma mãe de Zika, como muitos classificavam ainda na época, portanto, a presença e atenção de veículos midiáticos não era nenhuma novidade, tampouco a presença de uma equipe de 12 pessoas, entre os quais pesquisadores marcados por suas distintas línguas e sotaques.

De fato, a nossa experiência de pesquisa desde 2016 e os relatos que ouvimos sobre o primeiro ano da epidemia nos davam conta da excepcionalidade do Zika nos contextos de atendimento de crianças com deficiência ou doenças raras, ao passo que também já deram pistas sobre a normalização da "excepcionalidade" dessa experiência de atenção diferenciada. O que incontáveis vezes foi acompanhado por narrativas críticas que apontavam para o contraste com a ausência de atenção dispensada a outras condições experimentadas há anos pelas famílias e pessoas com deficiência. Um cenário totalmente novo em que uma emergência nacional e internacional em saúde está associada à experiência de pessoas com deficiência. Isso também desperta uma série de tensões na experiência dessas mulheres, uma vez que passado o foco na doença, é a cronicidade da condição que fica, é a experiência da deficiência nos corpos dos seus filhos que informa seu 
cotidiano; buscam, então, se afastar da noção de adoecimento, de doença, em narrativas que falam sobre a condição de "patológica" de seus filhos/suas filhas e que produzem fortes reações de rechaço por parte das mães. Comentários como "ele/ela não é doente, é saudável como qualquer criança", sugere essa necessidade de deslocamento do lugar de doença para o de deficiência. Contudo, o processo de medicalização do cuidado e a atenção dedicados à descoberta contínua da síndrome, uma vez que permanecem na condição de investigação dos sintomas e condições que surgem ao longo do desenvolvimento das crianças, torna essa definição e distanciamento sempre frágil e temporário, ao menos de acordo com os contextos específicos.

São 470 casos confirmados, 89 inconclusivos, 213 em investigação e 1.787 descartados. Como parte desse experimento e controle em saúde, todos os casos permanecem sendo acompanhados. Há uma disputa entre Estado e pesquisadores em torno dos encaminhamentos práticos direcionados a essas categorias: para os confirmados, tem-se como efeito um processo de construção e reelaboração das suas identidades a partir do diagnóstico, na constituição do que chamamos bioidentidades (RABINOW, 2007), que por sua vez, liga-se a experiência de construção identitária "pautada em condições biológicas"11 , a partir de um complexo identitário entre mãe-filhos/filhas, nomeados socialmente como bebês de micro e mães de micro, anjos e mães de anjos.

Para aqueles que permanecem em investigação (com diagnóstico não confirmado), e continuam alvo do escrutínio da ciência ${ }^{12}$, não se disponibiliza ainda a noção de normalidade ou de alta, eles não se encaixam nessa classificação. Tampouco se oferece um repertório capaz de produzir o reconhecimento e reelaboração de noção de pessoa a partir de uma condição específica mobilizada pelo diagnóstico de "microcefalia por Zika", ou as a partir das categorias de anjos ou micro, mães de anjos e mães de micro. Isto ocorre no caminho entre a confirmação do diagnóstico e a experiência cotidiana a partir deste, constituindo uma maneira específica de estar no mundo - uma bioidentidade - que decorre, por sua vez, numa biossocialidade (RABINOW, 1999), ou, nos termos de Rose (2007), a constituição de uma ação política organizada ancorada em torno de uma cidadania biológica ou ainda de cidadania 
terapêutica, segundo Nguyen (2010). Os casos "inconclusivos" e "em investigação" permanecem no radar das organizações de saúde e é periodicamente são convocados para novos exames a acompanhamento voltado para a aferição dos parâmetros de desenvolvimento das crianças. Uma classificação entre o estado considerado normal e patológico estabelece uma vida em suspeição contínua, e em estado de experimentação permanente. Petryna (2009) chama atenção para a linguagem de crise acionada em contextos como o da Pandemia HIV/AIDS, assim como a partir da adição de elementos do contexto social mais amplo:

Em lugares onde doenças graves e crônicas se misturam a transições políticas, guerras civis, turbulência civil e pobreza, a linguagem de crise tornou-se instrumental, dando legitimidade à experimentação que, em outras circunstâncias, seria negada. (PETRYNA, 2009, p. 128)

A linguagem de crise e emergência associada ao fenômeno desde as classificações dos órgãos de saúde, até a experiência das famílias no cotidiano de cuidados, baliza as práticas de pesquisa, justifica e reproduz a lógica da experimentação associada à oferta dos serviços em saúde no caso do Zika. A epidemiologista Celina Turchi, que ajuda a coordenar a rede de pesquisadores da Microcefaly Epidemic Research Group (MERG), que reúne mais de 30 profissionais de diferentes especialidades e instituições -, afirma que todo o processo de pesquisa foi acelerado, abreviando o tempo da burocracia associada às permissões, pareceres e acordos, bem como a liberação de recursos de financiamento de pesquisa oriundos de fontes diversas, incluindo a formação de grandes consórcios de redes de pesquisadores e de fomento à pesquisa ${ }^{13}$. O que só foi possível diante da perspectiva de crise, emergência e ameaça à saúde global, no que ela chama de "pesquisa em tempo de guerra", que difere por completo da experiência e dos processos necessários à implementação de "pesquisas em tempo de paz" ( SCOTT; LIRA; MEIRA, 2020). Justifica-se, pois, pela necessidade de respostas rápidas para contenção da crise e do estado de emergência, com implicações ainda pouco refletidas nesse contexto. Ao passo que cria um lastro para a normalização de práticas de pesquisa em contexto de emergência que perduram para além do período e da linguagem de crise, pela 
própria reprodução desses processos em meio à cronicidade da doença. A emergência continua a ser experienciada pelas mães e crianças em seus cotidianos (SCOTT; LIRA; MEIRA, 2020) e pelo próprio sistema de assistência à saúde em contínua "prioridade da prioridade" instaurada em face da resposta do Estado às demandas de serviços e cuidados institucionalizados para as crianças com SCZV (MATOS; QUADROS; SILVA, 2019).

As narrativas de dezenas de mulheres com as quais tenho convivido, conversado e seguido em seus percursos de vida sobre o momento da descoberta sugere a presença de elementos como insegurança, risco, medo diante do desconhecido, que continuam a conformar o tempo de crise e emergência. Vão desde os relatos sobre os primeiros momentos de diagnóstico e espanto (CARNEIRO; FLEISCHER, 2018) até o cotidiano de ciclos de sintomas e intercorrência que surgem e, em alguns casos, ressurgem ao longo do curso de vida das crianças, incluindo sintomas físicos ou experiências de vulnerabilidades múltiplas oriundas da excepcionalidade da condição, as quais emergem em diferentes momentos.

O aparato tecnológico proporciona a "verdade" sobre a condição de seus filhos, complementada por explicações variadas por parte dos profissionais, que produzem ainda mais dúvidas, medos, mais insegurança sobre sua nova condição no exercício da maternidade (CARNEIRO; FLEISCHER, 2018). Os relatos variam entre o choque, a descrença no diagnóstico, o medo, a tristeza que toma conta e engole tudo, o desespero que imobiliza, seguidos por um resgate emocional de si mesmas que pode levar algumas horas, alguns dias, meses, mas que expressam a luta constante e a necessidade de superação diante da condição anunciada, seja no período gestacional, seja após o nascimento da criança ${ }^{14}$.

É semelhante ao que ocorre no contexto de outras doenças raras reportadas como “[...] com grande potencial de alteração na vida dos sujeitos, tanto em função das limitações biológicas que acarretam quanto das incertezas geradas sobre seu prognóstico" (AURELIANO, 2018 , p. 373). Mas, como agravante, trata-se de uma nova patologia associada a um vírus pouco conhecido e com quase nenhum repertório 
tangível - efeitos e prognósticos pouco conhecidos, sem lastro nas experiências terapêuticas correntes, sem referências históricas outras para dar suporte ao novo cenário. Além disso, essa doença e suas sequelas se apresentam de forma coletiva, em meio a um surto sem precedentes e que abre caminho para muitas perguntas e respostas que vão emergindo paulatinamente no curso em que suas experiências como mães também se desenvolvem (SCOTT; LIRA; MEIRA, 2020). Então, apesar dessa experiência ser comum a mães com filhos que nascem com outras síndromes ou deficiência, podemos dizer que o contexto da Síndrome Congênita do Zika trouxe um elemento a mais para essa equação, pela expressão coletiva categorizada em situação de surto epidêmico e de consequências ainda imprevisíveis. Em muitos relatos os limites sobre tempo e condição de vida dos fetos nos prognósticos pré-natais intensificam a experiência do inesperado, o que apenas ganha seu tônus mais radical quando da descoberta da nova síndrome. A atmosfera de incerteza que cerca a epidemia do Zika (KELLY et al., 2020 apud CASTRO; NOGUEIRA, 2020) contribui para a constituição de uma experiência desorientadora.

É nesse contexto que as mães vão se reorganizar, o que significa entender a dinâmica do serviço de saúde aliado à pesquisa, compartilhar conhecimentos específicos e múltiplos advindos das descobertas científicas, bem como com outras mães na mesma condição, e organizar suas práticas cotidianas a partir de um outro repertório de interações.

Elas vivem em seu cotidiano uma série de práticas, linguagens, significados, emoções que envolvem o cuidado com seu filho ou filha com SCZ e que passa a orientar a própria percepção sobre si, seus projetos de vida, identidades e demais dimensões da sua existência, a busca de "verdades" biológicas e de "estratégias de intervenção". A bioidentidade, que se expressa, de forma extensiva em relação a filhos/as filhas, alimenta a biossocialidade dessas mulheres (RABINOW, 1999; 2007; VALLE, 2013, p. 8), diretamente relacionadas a uma miríade de conhecimentos produzidos por pesquisadores e pela rede de mulheres. Uma vida em descoberta constante parece definir em parte essa experiência. 
Na esfera do cuidado, permeado por conhecimentos e adaptações, é necessário lidar com aparatos e tecnologias, administrar uma série de medicamentos, sondas gástricas, bandagens, bottons, parapodios, cadeiras especiais, talas, adesivos, órteses, balão de oxigênio em alguns casos etc. Inclui também a convivência com uma diversidade de sintomas e comprometimentos que a síndrome impõe a seus filhos e filhas com graves condições neurológicas, motoras e fisiológicas.

Dos primeiros casos, descobertos e confirmados em meio ao primeiro momento do surto, aos diagnósticos seguintes, já amparados pela descoberta da síndrome, uma conjuntura de aparatos técnicos, tanto materiais quanto conceituais ${ }^{15}$ passou a permear o cotidiano dessa comunidade de mulheres e crianças. São vidas que passaram a lidar, do momento do diagnóstico em diante, com a condição simultânea de vida em tratamento, mas, especialmente, de vida em experimento (PETRYNA, 2011).

O mal-estar produzido por essa condição aparece nas narrativas de cansaço e falta de acesso às informações, na percepção de vivenciarem essa relação com essa técnica e esse saber na qualidade de cobaias, e se ressentirem por isso ${ }^{16}$. Por isso, em diversos momentos em campo ouvi afirmações categóricas sobre seus filhos/filhas não serem cobaias, numa clara demonstração de que era assim que se sentiam percebidas e tratadas. Tais experiências, por sua vez, são amenizadas pelo reconhecimento da necessidade da produção de conhecimento sobre a condição de seus filhos/filhas, especialmente a partir da noção pragmática de aperfeiçoamento das técnicas e tecnologias empregadas nos tratamentos ofertados.

Recife 24, fevereiro de 2018

Em evento realizado numa parceria entre uma universidade privada local e a Associação de Famílias Raras para marcar a semana de conscientização sobre Doenças Raras, pude acompanhar junto com outra pesquisadora e colega antropóloga, presente em outros relatos aqui, uma coleta de sangue das crianças com SCZV que chegavam para participar do evento. A coleta foi realizada numa espécie de hall, localizado atrás do auditório onde aconteciam as palestras. O evento tinha uma programação diversificada (palestra, apresentação de dança 
das crianças da associação de doenças raras, roda de conversa com coach em felicidade, entre outras atividades) e tinha entre o público presente mães-cuidadoras de crianças com outras Síndromes Raras, voluntárias da associação, pesquisadores e alguns profissionais de saúde.

Contudo, enquanto o público geral participava apenas como convidado de palestras sobre os avanços na pesquisa sobre Cri Du Chat, uma Síndrome Rara, e a possibilidade de relacionar essas pesquisas com a SCZV, entre tantas outras atividades, "as mães micro" eram encaminhadas para a coleta de sangue de seus filhos. Uma equipe com enfermeira e assistentes do pesquisador palestrante organizava as mães, fazia perguntas, anotava nas pranchetas sobre cada criança, e iniciava a coleta. Receosas e desconfortáveis, as mulheres foram encaminhadas com suas crianças para esse local. Era uma coleta de sangue para pesquisa genética realizada em formato de mutirão.

Assisto à coleta de sangue de duas crianças cujas mães venho acompanhando há meses em campo. Após quatro tentativas de coleta, Letícia já estava aos prantos, chorava muito alto nos braços de Joana, sua mãe, que também não segurou o choro, e pediu para interromper aquele procedimento, mesmo diante da insistência da equipe. Não era a primeira vez que era muito difícil coletar sangue de Letícia, os relatos de outras mães se somavam ao de Joana, seria mais difícil coletar sangue dos "bebês de micro", segundo contavam. A pressão era enorme e era possível ver todo o dilema de Joana em continuar ou não a se submeter a esse processo. Por fim, ela solicitou que interrompessem a coleta, já que havia, na percepção dela, sangue suficiente para realizar exames, no que a equipe concordou.

Luísa, por sua vez, já sentou na cadeira com muita desconfiança e desconforto. Ela não chorou quando duas tentativas de coleta sem sucesso foram realizadas em Maria, mas sua expressão tinha outra conotação de sofrimento, tinha uma substancialidade que mais se aproximava do sentimento de indignação ou revolta. Maria foi furada três vezes, Luísa se ressentia a cada tentativa e expressava isso em palavras e expressões faciais bastante intensas, ela não permitiu mais furadas em Maria, mas, diante da insistência da equipe, avisou que voltaria para outra tentativa após assistir à palestra que acontecia 
no auditório ao lado. Joana perguntou ainda quando receberia os resultados, porque lembra que um ano atrás passou pelo mesmo processo com a mesma equipe e nunca recebeu nada. A resposta é evasiva, não transmite firmeza e nem certeza por parte da equipe se e quando elas receberão esses resultados. Nos gestos e expressões faciais, no controle tenso dos corpos de suas filhas que choravam e se debatiam e de seus próprios corpos, toda a angústia e desconfiança, o desconforto moral e emocional de estar ou não fazendo a coisa certa. Corporalmente pareciam reprovar toda aquela situação. Outras mães chegavam com seus filhos no colo, algumas com menos desconfiança, mas com expressões sutis de desconforto. Todavia, resilientes, cumpriam o protocolo.

No Estado de Pernambuco, e possivelmente em outras regiões onde houve um número significativo de casos da SCZV, atendimento e pesquisa caminharam juntos do início da epidemia até o presente momento, o que marcou de forma inédita a relação entre Política pública de atendimento, serviços de saúde e pesquisa no estado. Se por um lado, essa relação foi estratégica para uma intervenção mais eficiente para prevenção e atendimento das famílias, também instaurou uma dinâmica de controle sobre os corpos das crianças e das mães. É no domínio sobre a corporeidade dos sujeitos que o biopoder se expressa: nas coletas de sangue, em mutirões de exames para diagnóstico e pesquisa - nas articulações entre atendimento e experimento ${ }^{17}$.

De uma hora para outra, essas mulheres precisaram se apropriar de códigos próprios à área médica, precisam ter o olhar atento para comunicar aos profissionais qualquer mudança, qualquer sintoma novo, treinar o olhar com parte do repertório que associaram pela relação com pesquisa e atendimento. Esse cuidado assume um viés medicalizado, norteado pela concepção e pela técnica biomédica/investigativa. São rotinas de exames e mutirões de diagnóstico e pesquisa, as quais pouco se tem acesso enquanto "objeto", aos resultados. Toda essa atenção medicalizada incorporada pelas mães, passa por processo de adaptação por parte das famílias que lhes permite uma série de inferências e o desenvolvimento de estratégias nem sempre devidamente reconhecidas pelo saber médico, e que por vezes lhes nega o compartilhamento 
detalhado dos resultados das pesquisas e das análises diagnósticas e terapêuticas em andamento. Instauram-se relações ambíguas que alternam entre práticas de cooperação entre esses dois grupos e modelos de conhecimento (profissionais/pesquisadores de saúde e mãescuidadoras) por um lado, e ausência de cooperação e de reconhecimento recíproco, especialmente dos profissionais em relação às mães, por outro lado. Em momentos como os mutirões de pesquisa/atendimento que acompanhei, durante os procedimentos de exames diagnósticos, pude observar as conversas e análises sobre tais condições que aconteciam na presença das mães e sem nenhum compartilhamento direcionado para elas - tão objetificadas quanto as crianças nesse tipo de interação.

Contudo, para além dos diagnósticos e da condição de "anormalidade" imposta pela presença constante desses aparatos e modelos de interação, as mães reelaboram os limites e oferecem escapes importantes e noções contrastantes de normalidade, de progresso, desenvolvimento e valor da vida, num esforço constante de reconhecer a diferença, sem ampará-la em critérios exclusivistas em relação à condição de seus filhos e filhas. De forma semelhante, também conseguem realizar as adaptações necessárias na prática cotidiana do cuidado, criando não apenas o que Diniz (2016) chamou de "Ciência Doméstica", mas técnicas e tecnologias adaptativas domésticas "nativas", ao lançar mão de um aparato mais próximo de suas realidades. Isso ocorre na manipulação de medicamentos, suplementos, sondas, "órteses caseiras", suportes para banhos terapêuticos, cadeiras para alimentação e técnicas para manutenção da posição preconizada pelas profissionais de fisioterapia, instrumentos de estimulação precoce etc. (FLEISCHER, 2017). São procedimentos altamente inventivos e que constroem algum sentido de controle sobre a experiência da maternidade, acionando noções de autonomia nesse campo de disputas em torno do cuidado, da vida e destino do complexo mãe-filhos/as com SCZV.

\subsection{Pesquisa, Assistência e Intervenção Filantrópica}

Segundo Rabinow e Rose (2006, p. 29), podemos perceber a emergência de "[...] um ou mais discursos de verdade sobre o caráter 'vital' dos seres humanos, e um conjunto de autoridades consideradas 
competentes para falar aquela verdade [...]; estratégias de intervenção sobre a existência coletiva em nome da vida e da morte [...]", os quais produzem modos de subjetivação. Nesse sentido, a vida, em condição dupla de tratamento/experimento, tem lugar num continuum que sugere a desconexão com formas de vida traduzíveis em signos de normalidade, e ainda sugerem a ausência de controle e poder por parte dos sujeitos em investigação/terapia - as crianças e suas mães. A vida definida em nomenclaturas e números nas tabelas epidemiológicas se processa em modos de subjetivação específicos, constituídos a partir dos sujeitos, mas com material fornecido pelas instituições em limites bem mais rigorosos que aqueles experimentados em condições de existência que se enquadram na noção de normalidade em vigor. O "poder sobre a vida" do qual falam Rabinow e Rose (2006), transpõe e passa a operar no âmbito das relações entre os polos micro e macro, que podem de um lado, enfatizar "[...] os modos de pensar e agir ao nível dos grupos populacionais e coletividades, variavelmente definidos; e, do outro lado, a individualização de estratégias biopolíticas" (RABINOW; ROSE, 2006, p. 38 $)^{18}$.

\section{Luciana}

Essa realidade se expressa, por exemplo, nos limites das notificações de casos pela vigilância sanitária: algumas vezes esses limites e direcionamentos são interpretados pelas próprias mulheres como o fato da inserção nos sistemas privado ou público acarretar registros e controle distintos sobre a condição de saúde das crianças com SCZ. Em momento de conversa com as mulheres, elas chamam atenção para o fato de que os casos de crianças com os mesmos sintomas e nascidos no período reconhecido dentro do espectro do surto de microcefalia nos hospitais particulares da região não passaram pelos mesmos procedimentos para diagnóstico e controle por parte do Estado. Existe, de acordo com essa percepção, um procedimento flexibilizado em relação ao controle efetivo nas unidades públicas e privadas, que gera, por sua vez, desconfiança ou suposição sobre uma possível subnotificação de casos nesses espaços, advinda da falta de controle do Estado sobre os usuários do sistema privado - as famílias de classe média e alta. De modo semelhante, as crianças das camadas 
sociais mais privilegiadas diagnosticadas com a Síndrome não estão presentes nas salas de atendimento dos serviços de terapia e reabilitação das instituições públicas, e quando estão, trata-se de uma presença mais pontual e menos afeita à gama de relações intensas com outras famílias afetadas, com algumas exceções notórias de mães que mesmo não frequentando o serviço público de atendimento, se engajam nas associações (alguns poucos casos, de fato). Consequentemente, confere maior distanciamento em relação ao controle exercido pelo binômio pesquisa-atendimento, e maior autonomia em relação ao escrutínio da ciência. O controle sobre os corpos e rotinas de crianças com SCZ e de suas mães-cuidadoras - a partir da noção de corpos e identidades extensivas de Scott et al. (2017) - assume um viés de classe importante e definidor.

Cientes dessa relação e da majoritária condição de vulnerabilidade socioeconômica que caracteriza as famílias atingidas pela epidemia, centros de atendimento e reabilitação, em associação com equipes de pesquisa, acionam estratégias que aliam prestação de serviço-pesquisa às práticas e discursos filantrópicos ou de cunho assistencial. É o caso de uma das instituições de referência no atendimento das crianças com a SCZV que, a partir de um projeto, articula o atendimento já ofertado às famílias ao exercício de uma pesquisa de grande porte realizada a partir de um convênio com o Governo dos Estados Unidos ${ }^{19}$. A pesquisa teria caráter multidisciplinar e duração de 5 anos, durante os quais em média 200 famílias, selecionadas pelo centro de atendimento, seriam acompanhadas para fins terapêuticos e científicos ao mesmo tempo; prevê também o uso de tecnologias fornecidas pelos prestadores/ cientistas estrangeiros para testes de eficiência e aprimoramento tecnológico, e também uma extensa e contínua pesquisa social, cuja coleta ocorre entre atendimento e outras coletas de caráter mais biologizante, como exames e coleta de material das mães e das crianças. Condicionado à participação e assiduidade nas etapas do Projeto de extensa e diversa pesquisa-intervenção, as mulheres recebem doações mensais de itens de necessidade básica, como fraldas, leite e, de maneira mais regular, cestas básicas. 
A imbricação entre as esferas do atendimento, pesquisa e filantropia é de tal ordem que em diversas ocasiões o dia de "buscar a cesta" é também o dia de participar de pesquisas, respondendo a questionários aplicados numa sala reservada. Uma das interlocutoras que acompanhei nessas ocasiões explica que é dia de "responder de novo aquelas entrevistas", sem saber muito bem o porquê ou para que servem. Trata-se de entrevistas estruturadas e semiestruturadas aplicadas por profissionais da instituição de forma regular. Há também festas e passeios promovidos pelo Projeto para as participantes, bem como a oferta de aparelhos para testes, que posteriormente são devolvidos para a instituição com dados registrados nos próprios aparelhos ou pelas mães, orientadas a fornecer informações a respeito do uso do equipamento; há também um veículo especial usado para transportálas e aos seus filhos/suas filhas da casa ao centro de atendimento e de volta para casa nos dias que o atendimento ocorre pelo Projeto ${ }^{20}$.

As disputas em torno do acesso à pesquisa nesses ambientes institucionais, que também realizam suas próprias pesquisas - em convênio ou não com outras instituições de pesquisa -, costumam constituir um obstáculo para a entrada de pesquisadores não vinculados aos mesmos. É o caso da instituição descrita na situação anterior, que negou a permissão para realização de pesquisa da nossa equipe com profissionais e/ou usuários dos seus serviços, alegando a relação de exclusividade com a pesquisa realizada em convênio com o governo norte americano. Tal dificuldade também foi enfrentada por outros pesquisadores em instituições do estado que prestam atendimento às famílias, tanto aquelas subsidiadas, quanto algumas da própria rede do SUS.

As respostas das mulheres às relações tecidas pelos pesquisadores e instituições vinculadas com elas e suas crianças no campo da Síndrome Congênita do Zika, são múltiplas: de fato, o cansaço, a desconfiança ( saturação), o desinteresse "com esse povo que só faz pergunta", como classificou Joana, mãe de Letícia, se manifesta com bastante frequência. Contudo, nossas interlocutoras consideram, valorizam a opinião e a construção do conhecimento por parte daqueles que pesquisam a condição de seus filhos/suas filhas, e costumam responder 
e participar de diversas pesquisas em nome desse reconhecimento, inclusive quando esse escrutínio da ciência ocorre em procedimentos fisicamente invasivos ou no cotidiano da clínica. Tudo em busca de respostas para a condição que experimentam no cotidiano cercado de lacunas e adaptações, numa procura incessante de uma melhor condição para seus filhos/suas filhas e para si. Aos incômodos às vezes respondem com resiliência, outras vezes subvertem a ordem e acionam práticas de resistência, como as adaptações e ressignificações das prescrições médico-científicas, mas também a partir de uma agência política notória, capaz de mobilizar profissionais do Brasil e o do exterior ${ }^{21}$.

O $54^{\circ}$ Congresso da Sociedade Brasileira de Medicina Tropical, realizado no Recife entre 3 e 5 de setembro de 2018, foi um exemplo notável: foi o palco, não planejado, das demandas dessas mulheres por acesso à informação e por relações mais éticas e horizontais entre pesquisadores e pesquisados. A reivindicação veio em forma de manifesto, uma nota de repúdio que havia sido lançada nas redes sociais, em reação a não inclusão das famílias afetadas pela SCZV na programação do evento. Foi lida pela presidente da UMA numa das mesas organizadas no congresso com pesquisadores de um grande conglomerado de pesquisa em Pernambuco. A leitura da nota realizada pela presidente da Associação num grande anfiteatro no Centro de Convenções de Pernambuco durante o evento, causou grande impacto e comoção na plateia formada majoritariamente por pesquisadores, gestores públicos e profissionais de saúde. Segue a nota:

\section{Boa Noite}

Sou Germana Soares, mãe da Geovanna de 11 meses e do Guilherme com 2 anos e 9 meses. Ele é uma Pessoa com Deficiência. Tem a Microcefalia derivada da Sindrome Congênita do Zika Vírus. Sou mulher, negra, pobre, mãe de PCD, divorciada, chefe de família, fonte de inspiração e por muitas vezes, inúmeras, material de pesquisa.

Devido a consciência da omissão por políticas públicas resolvi fundar a UMA (União de Mães de Anjos) que cuida e acolhe mães e familiares com SCZV, hoje com 409 associados em todo o estado de Pernambuco.

Venho por meio desse instrumento externar a minha total indignação com a organização do $54^{a}$ Congresso da Sociedade Brasileira de Medicina Tropical por não achar importante Convidar/Comunicar/Avisar a mim e a UMA sobre este evento. Nós somos as maiores vítimas, sobre qualquer 
circunstância da Epidemia do Zika, já que somos a instituição de coletivo de mães referência no mundo.

Achamos de uma falta de empatia e sensibilidade com a nossa realidade, uma tamanha falta de respeito em nos subestimar e achar que nós mães, familiares, cuidadoras, não teríamos a compreensão de um evento técnico sobre o NOSSO maior interesse, pois se existem pessoas com o mais interesse em saber absolutamente tudo sobre o Virus Zika, somos nós, que enfrentamos e vivemos todos os dias a pior face desse inimigo desconhecido.

Queremos ser parceiras, colaborar, contribuir, fazer parte da construção, entender as descobertas para que todos andem de mãos dadas. As homenagens oferecidas de pessoas/profissionais que investiram tempo e empenho para avanços nessa área deveriam ser entregues por nós. Ou melhor, muito melhor, alguém ter a humildade de nos traduzir o porquê que aquela pessoa/profissional fez de tão espetacular com base em nossos filhos que não sabemos?

Será que nós mães somos tão ignorantes, sem o minimo de instrução que não saberíamos entender um artigo científico ou uma palestra? Ou os profissionais que deveriam ter uma linguagem de fácil entendimento? Ou estamos totalmente equivocadas em querer exigir a discussão sobre ética em pesquisa dentro da biomedicina? Será que somos apenas números? Apenas estatísticas?

Enquanto vocês fazem seu evento, recebem suas homenagens ou sentam numa mesa como palestrante existe uma geração de crianças e famílias afetadas pela SCZV tentando compreender como alguns profissionais podem ser tão frios e não perceberem na prática que lidam com seres humanos, exatamente iguais a si mesmos.

Respeitem nossa causa,

Respeitem nossas histórias,

Respeitem nossa realidade.

Respeitem!

Nada sobre nós sem nós

(Carta aberta ao $54^{\circ}$ Congresso da Sociedade Brasileira de Medicina Tropical, 8 de setembro de 2018)

A utilização do lema "Nada sobre nós sem nós"22, tradicionalmente utilizado pelos movimentos das pessoas com deficiência, especialmente a partir dos anos 1980 (CHARLTON, 1998), foi a tônica do discurso proferido por Germana Soares, presidente da União de Mães de Anjos, para expressar: a demanda das famílias em torno da maior participação nos espaços de discussão e divulgação das descobertas científicas, por 
maior transparência nos procedimentos e pela devolutiva dos resultados, assim como pela apresentação dos resultados de forma acessível para as famílias afetadas, que constituem a parte mais interessada na produção desse conhecimento. A busca por acesso às implicações e resultados das pesquisas, às explicações produzidas pela ciência sobre a condição de vida de seus filhos/suas filhas e delas próprias, revestese de uma ação política de busca por autonomia e controle sobre seus corpos, os corpos das crianças, suas vidas, a vida das crianças afetadas - a busca por autonomia e direito à vida que não se limite à condição de experimento, "nossos filhos não são cobaias", afirma a presidente da UMA após ler a carta.

\section{Helena}

Estas reivindicações não aconteceram somente nesta ocasião. Se a fala da presidente da UMA no $54^{\circ}$ Congresso da Sociedade Brasileira de Medicina Tropical foi um evento particularmente comentado entre os pesquisadores de ciências sociais que acompanham as mães, também por conta da visibilidade do evento, nem sempre foi num consenso geral: a demanda por uma relação de troca, ou melhor de retribuição, entre pesquisadores e pesquisados, gerou um certo desconforto dentro da tradição metodológica de coleta de dados dos cientistas sociais embora a questão da empatia seja bastante discutida.

Em outro evento científico, ocorrido anteriormente em 2018, um Workshop organizado no âmbito pré-ABRASCO (Associação Brasileira de Saúde Coletiva), mães representantes de diversas associações ligadas à SCZV foram convidadas a participar. Após um espaço de fala dedicado às mães, logo na introdução do workshop, todos os participantes foram distribuídos em grupos de trabalho segundo seus interesses. Durante o grupo de trabalho sobre tecnologias de diagnóstico, uma mãe questiona a prática do "consentimento esclarecido" pelos biomédicos: "não sabemos o que assinamos, e depois fico sabendo que o sangue do meu filho foi enviado pro outro lado do mundo. Nunca tive nenhum retorno sobre essas pesquisas". No mesmo grupo, ao ouvir um virologista especialista de arboviroses comentar sobre a "fantástica oportunidade" de se pesquisar pessoas atingidas pelo vírus, essa mesma mãe vira e 
retruca: "somos seres humanos, como pode falar de nós assim? Não somos objetos!".

A investigação durante e após o período da epidemia do vírus Zika trouxe à tona questões fundamentais para o trabalho do pesquisador, seja ele da área de biomedicina, epidemiologia, ou de ciências sociais. A relação pesquisador/sujeito de pesquisa é questionada pelas próprias famílias que acompanhamos e nos levam à responsabilidade de pensar melhor sobre a questão da objetificação, intimamente ligada com a concorrência na produção de dados em tempos de emergência sanitária.

\section{Considerações Finais}

Quando pensamos a construção deste texto, nos orientamos por nossas experiências a partir dos diferentes caminhos e trajetórias em campo, uma pesquisadora local e outra "estrangeira" e as diferentes camadas de distanciamento e aproximações que podem resultar desses lugares. Encontramos, contudo, nesses diferentes caminhos respostas eloquentes sobre as relações tecidas por pesquisadores/pesquisadoras com as mulheres que experimentam desde o nascimento de seus filhos/ suas filhas com a Síndrome Congênita do Zika Vírus. Essas relações se constituem num estreitamento de vínculos, e são muitas vezes atravessadas pela oferta de serviços de saúde, e as práticas de cuidados e os modos de subjetivação acionados pela experiência da vida em tratamento, em experimento. No que tange as percepções sobre esses vínculos, nos deparamos com relações ambíguas, ora de cooperação e sentimento de partilha, de informações e tratamentos possíveis, bem como informações que podem elucidar as lacunas e ausências numa condição ainda pouco conhecida e sem amparo em experiências anteriores; por outro lado, revela as tensões, desconfianças e críticas em relação aos processos de objetificação aos quais estão sujeitas mulheres e crianças nesse contexto a partir de práticas de pesquisa/atendimento. Essas práticas muitas vezes acabam desconsiderando o lugar de sujeitos interessados nos resultados e na partilha de conhecimento, tanto quanto nas discussões sobre os modos desse fazer científico, mobilizando categorias como direito à informação e ética em pesquisa, mesmo 
diante da distância de linguagens e domínios técnicos, bem como de legitimidade sobre tais interesses.

Acionam uma linguagem e performance de resistência, como na postura de protestos em eventos científicos, nos discursos e narrativas sobre as adequações possíveis e viáveis dos protocolos em saúde as suas realidades cotidianas. O que pode significar a produção de novos modos de subjetivação, de acordo com Caponi (2004), atuando sobre a produção e exercício da biopolítica. É o que ocorre no processo de reelaboração das noções de normalidade e desenvolvimento, no engajamento político das mulheres (as mães de anjos, mães especiais, mães raras), articuladas em torno de uma experiência dupla de submissão e resistência aos modos de subjetivação produzidos institucionalmente, por quem exerce o controle sobre a vida e a define enquanto tal, como evidenciam as discussões produzidas nos estudos da deficiência, também relacionadas aos movimentos das pessoas com deficiência (DINIZ, 2003; GARDOU, 2006; SANTOS, 2008; MELLO; NUERNBERG, 2012). Uma nova subjetividade emerge a partir das relações constituídas com essas instâncias de poder, produzidas pela ciência e pelo sistema de atenção à saúde, por seus aparatos técnicos e sua linguagem, por uma lógica institucional que passa a organizar suas vidas em função do tratamento, controle e investigação sobre as crianças e suas cuidadoras.

A condição ambivalente que permeia a relação dos sujeitos (crianças acometidas pela SCZ e sua mãe-cuidadora) nas experiências de relação com o Estado e seus aparatos institucionais e conceituais, e no exercício do biopoder sobre seus corpos e subjetividades, a apropriação e ressignificação desse processo a partir da inversão ou flexibilização dos seus termos, conduz a uma biopolítica capaz de produzir novos modos de subjetivação. Esses novos modos de subjetivação subvertem, em termos simbólicos e políticos, as relações de poder, mesmo estando inextricavelmente emaranhadas nas redes institucionais dessas relações; mas, conscientes dessas relações, apontam para elas, as desvendam e reorganizam-nas de acordo com seus parâmetros. 


\section{Notas}

1 Uma versão resumida deste texto foi apresentada no Colóquio Os Mil Nomes de Gaia (Rio de Janeiro, setembro de 2014), e publicada na série Pandemia de cordéis, da editora n-1. O exercício de "economia geral" (para usar a nomenclatura de Georges Bataille) aqui exposto deve, mais do que seria possível expressar em palavras, ao auxílio e pesquisas de Flávia Cera (em especial, sua tese de doutorado citada adiante), a quem dedico não só este texto, mas o horizonte de um futuro possível que ele tenta sondar e que espero que possamos ajudar a construir com e para nosso filho Caetano.

2 “Qu'est-ce que le virus Zika?", "Faut-il avoir peur du virus Zika?", "Zika, la nouvelle menace venue des moustiques.", "Des malformations pour des dizaines de milliers de bébés.", "Zika, le virus qui menace les bébés brésiliens.", "Le virus Zika, dangereux pour le cerveau des bébés".

3 The tip of the iceberg. Zika epidemic and microcephaly risk: Global health emergency VS biopolitics and social inequalities regarding perinatal care in Brazil, Institut Francilien Recherche Innovation Société, voltado para as Science and Technology studies, 2017-2018.

4 A respeito da atuação dos antropólogos e da relação de confiança das populações para com os pesquisadores durante a epidemia de Ebola, ver por exemplo as redes online: Réseau ouest Africain Anthropologie des Epidémies Emergentes (https:// shsebola.hypotheses.org/l), The Social Science in Humanitarian Action Plataform (http://www.ebola-anthropology.net/), Ebola Response Anthropology Platform (https://www.socialscienceinaction.org/).

5 Ver Diniz (2016) para um relato da Science in the making, partindo da observação dos clínicos gerais e profissionais de beira de leito no Nordeste, até as pesquisas sobre gestantes e o vírus Zika dos neurocientistas e biólogos das instituições mais renomeadas do país.

6 Edital MCTIC/FNDCT-CNPq/MEC-CAPES/MS-Decit n. 14/2016 - Prevenção e Combate ao vírus Zika.

7 Financiamento Newton Research Collaboration Programme/FACEPE, parceria institucional entre FAGES/UFPE, IDS/University of Sussex, UnB, Fiocruz Rio de Janeiro.

8 Condições como AME - Atrofia Muscular Espinhal, Cri Du Chat, Síndrome de West, Síndrome de Rett, Paralisia Cerebral, Síndrome de Down, Transtorno do Espectro Autista, entre outras.

9 Importante ressaltar que essas tensões não excluem a possibilidade frequente de relações harmoniosas e sentidas pelas mães como cooperativas. De fato, acontece com intensa regularidade, no entanto não elimina as críticas aos possíveis abusos nas relações de pesquisa ou, apenas, a percepção dos ganhos em termos de prestígio e notoriedade para os pesquisadores e boa parte dos profissionais de saúde que prestam serviços fundamentais às crianças e realizam suas pesquisas concomitantemente.

10 Outros casos de campos "saturados" ou de povos "over-researched" por várias gerações de antropólogos já são conhecidos: os Bushmen do Bostswana, os Índios Navajos da América do Norte, os Dogons do Mali entre outros.

11 O mesmo ocorre entre a AIDS e o câncer por exemplo, negligenciado pelo mercado financeiro das pesquisas científicas, da indústria farmacêutica, e consequentemente pelos pesquisadores na África (LIVINGSTON, 2012). 
“Nossos filhos não são cobaias": objetificação dos sujeitos de pesquisa e saturação do campo...

12 Sobre políticas identitárias no contexto da Pandemia HIV/AIDS em Valle (2002), Biehl (2007) e Rose (2007).

13 Os casos suspeitos não descartados seguem uma rotina anual de exames, testes e acompanhamento relativo ao desenvolvimento neuropsicomotor das crianças, já que em diversos casos foi possível a detecção tardia da SCZV, especialmente para as crianças que nasceram sem a microcefalia, considerado, inicialmente, principal critério de diagnóstico.

${ }^{14}$ Entrevista concedida às pesquisadoras $\mathrm{X}$ e $\mathrm{Y}$, integrantes da pesquisa $\mathrm{X}$.

15 Experiência compartilhada por outras condições e discutida no campo dos Estudos da Deficiência, por exemplo em Wachtel e Carter (2008).

${ }^{16}$ Com a elaboração de protocolos de atendimento e diagnose, por exemplo, políticas específicas constituídas por meio de portarias ministeriais responsáveis pela implementação de diversas políticas públicas (como a prioridade no acesso ao BPC, ao Programa Minha Casa, Minha Vida, ao Vem Livre acesso, entre outras), procedimentos, práticas e uma linguagem específica.

17 O campo saturado, muitas vezes relacionado com questões de saúde, observa Chabrol (2008, p. 239), é impregnado de expressões de “cansaço, ressentimento e suspeitas" voltadas para o pesquisador.

18 Ver Biehl (2007) e Comaroff (2007) sobre essa relação de pesquisa e intervenção em políticas globais de saúde de HIV/AIDS, especialmente voltados para as regiões periféricas do Sul global, e a biopolítica direcionada para as populações vulneráveis de tais regiões.

19 Como ocorre em outros contextos de pesquisa, realçados nos trabalhos de Rose (2007) e Valle (2013).

20 Essa foi a descrição realizada durante a apresentação do Projeto para as mães pela equipe da instituição e é assim explicado nas narrativas das mães.

${ }^{21}$ Até o momento que estive durante o campo na instituição, no fim de 2018, nem todas as mães e crianças tinham acesso a esse transporte específico.

22 Ver a discussão de Comaroff (2007) relacionada ao contexto do ativismo HIV/AIDS com foco na crítica sobre a formação de "biocapital".

23 A origem desse lema remonta ao Renascimento, num contexto de demandas por participação nas tomadas de decisão por parte de grupos sociais específicos. No contexto desta pesquisa, alinha-se ao seu uso associado às demandas por participação política dos movimentos da pessoa com deficiência.

\section{Referências}

ABRAMOWITZ, Sharon. Epidemics (Especially Ebola). Annual Review of Anthropology, [S.l.], v. 46, p. 421-45, 2017.

AURELIANO, Waleska de Araújo. Trajetórias Terapêuticas Familiares: doenças raras hereditárias como sofrimento de longa duração. Ciência $\boldsymbol{\sigma}$ Saúde Coletiva, [S.l.], v. 23, n. 2, p. 369-379, 2018.

BIEHL, João. Will to live: AIDS therapies and the politics of survival. Princeton: Princeton University Press, 2007.

CAPONI, Sandra. A biopolítica da população e a experimentação com seres humanos. Ciência \& Saúde Coletiva, [S.l.], v. 9, n. 2, p. 445-455, 2004. 
CARNEIRO, Rosamaria; FLEISCHER, Soraya. "Eu não esperava por isso. Foi um susto": conceber, gestar e parir em tempos de Zika à luz das mulheres de Recife, PE, Brasil. Dossiê Zika vírus: uma epidemia em/e seu mundo social. Interface: Comunicação Saúde e Educação, [S.l.], v. 22, n. 66, p. 709-19, 2018.

CASTRO, Luísa Reis; NOGUEIRA, Carolina. Who Should Be Concerned? Zika as an Epidemic About Mosquitoes and Women (and some reflections on COVID-19). Somatosphere, abril 2020. Disponível em: http:// somatosphere.net/2020/zika-epidemic-mosquitos-women.html/. Acesso em: 5 maio 2020.

CHABROL, Fanny. Enquêter en milieu convoité. Les terrains surinvestis de l'anthropologie. In: BENSA, Alban et al. (org.). Les politiques de l'enquête. La Découverte: Recherches, 2008. p. 229-244.

CHARLTON, James. Nothing about us without us: disability oppression and empowerment. California: University of California Press, 1998.

COMAROFF, Jean. Beyond Bare Life: AIDS, (Bio)Politics, and the Neoliberal Order. Public Culture, Duke University Press, v. 19, n. 1, p. 197-219, 2007.

DAS, Veena. Violencia, Cuerpo y Lenguaje. Uribe: Colección umbrales, 2016.

DINIZ, Débora. Modelo social da deficiência: a crítica feminista. Série Anis: 28, 2003. p. 1-8.

DINIZ, Débora. Zika: do Sertão nordestino à ameaça Global. Rio de Janeiro: Civilização Brasileira, 2016.

DOZON, Jean-Pierre. L'anthropologie à l'épreuve de l'implication et de la réflexion éthique. In: AGIER, Michel (org.). Anthropologues en danger: L'engagement sur le terrain. Paris: éditions Jean-Michel Place, 1997. p. 109-121.

FLEISCHER, Soraya. Segurar, caminhar e falar: notas etnográficas sobre a experiência de uma "mãe de micro" no Recife/PE. Cadernos de Gênero e Diversidade, [S.l.], v. 3, n. 2, maio-ago. 2017.

GARDOU, Charles. Quais são os contributos da Antropologia para a compreensão das situações de deficiência? Revista Lusófona de Educação, [S.l.], v. 8, p. 53-61, 2006.

LIRA, L. C.; SCOTT, R. P.; MEIRA, F. S. Trocas, Gênero, Assimetrias e Alinhamentos: experiência etnográfica com mães e crianças com síndrome congênita do Zika. Revista Anthropológicas, [S.l.], ano 21, v. 28, n. 2, p. 206-237, 2017. 
LIRA, L. C.; SCOTT, R. P.; SOUZA, F. M. Microcefalia não é o fim: corpo, afeto e noção de pessoa no contexto da Síndrome Congênita do Zika Vírus. In: $18^{\circ}$ CONGRESSO MUNDIAL IUAES - INTERNATIONAL UNION OF ANTHROPOLOGICAL AND ETHNOLOGICAL SCIENCES, Universidade de Santa Catarina, 2018. Anais [...]. Florianópolis, SC, 2018.

LIVINGSTON, Julie. Improvising Medicine: an African Oncology ward in an Emergency Cancer Epidemic. Duke: Duke University Press, 2012.

MAIA, Luis et al. Colaborações científicas em Zika: identificação dos principais grupos e pesquisadores através da análise de redes sociais. Cadernos de Saúde Pública, [S.l.], v. 35, n. 3, 2019. Disponível em: http://www.scielo.br/scielo.php?script=sci_arttext\&pid $=$ S0102-311X20190 $003050068 \operatorname{lng}=$ ensnrm $=$ iso. Acesso em: $\overline{3}$ maio 2020.

MATOS, S. S.; LIRA, L. C.; MEIRA, F. Deficiência, Ativismo, Gênero e Cuidado na Síndrome Congênita do Zika Vírus. Revista Anthropológicas, [S.l.], v. 29, p. 142-153, 2018.

MATOS, Silvana; QUADROS, Marion; SILVA, Ana Cláudia Rodrigues. A negociação do acesso ao Benefício de Prestação Continuada por crianças com Síndrome Congênita do Zika Vírus em Pernambuco. Anuário Antropológico, [S.l.], v. 44, n. 2, p. 229-260, 2019.

MELLO, Anahi Guedes de; NUERNBERG, Adriano Henrique. Gênero e deficiência: interseções e perspectivas. Estudos Feministas, [S.l.], v. 20, n. 3, p. 635-655, 2012.

MLAKAR, Jernej Misa et al. Zika Virus Associated with Microcephaly. New England Journal of Medicine, [S.l.], v. 374, n. 10, p. 951-958, 2016. DOI: https://doi.org/10.1056/NEJMoal600651.

NATURE NEWS, Nature's 10, [S.l.], v. 540, n. 7.634, p. 507, 2016.

Disponível em: https://www.nature.com/news/nature-s-10-1.21157\#turchi. Acesso em: $1^{\circ}$ maio 2020.

NGUYEN, Vinh-Kim. The Republic of Therapy: Triage and Sovereignty in West Africa's Time of AIDS. London: Duke University Press, 2010.

PETRYNA, Adriana. When experiments travel: clinical trials and the global search for human subjects. Princeton: Princeton University Press, 2009.

PETRYNA, Adriana. Experimentalidade: ciência, capital e poder no mundo dos ensaios clínicos. Horizontes Antropológicos, Porto Alegre, ano 17, n. 35, p. 127-160, jan.-jun. 2011.

RABINOW, Paul. Antropologia da Razão: ensaios de Paul Rabinow. Rio de Janeiro: Relume Dumará, 1999. 
RABINOW, Paul. Afterword: concept work. In: GIBBON, Sahra; NOVAS, Carlos (org.). Biossocialities, genetics and the social sciences: making biologies and identities. New York: Routledge, 2007.

RABINOW, Paul; ROSE, Nikolas. O conceito de biopoder hoje. Política e Trabalho - Revista de Ciências Sociais, [S.l.], n. 24, p. 27-57, abril de 2006.

ROSE, Nikolas. The politics of life itself: Biomedicine, power, and subjectivity in the $21^{\text {st }}$ Century. Princeton: Princeton University Press, 2007.

SANTOS, Wederson R. Pessoas com Deficiência: nossa maior minoria. Physis, [S.l.], v. 18, n. 3, p. 501-519, 2008.

SCOTT, R. P. et al. A Epidemia de Zika e as Articulações das Mães num Campo Tensionado entre Feminismo, Deficiência e Cuidados. Cadernos Gênero e Diversidade, [S.l.], v. 3, n. 2, p. 73-92, maio-ago. 2017.

SCOTT, R. P.; LIRA, L. C.; MEIRA, F. S. A gestão do tempo no tempo da emergência: o cotidiano das mães e crianças afetadas pela Síndrome Congênita do Zika. Ayé: Revista de Antropologia, [S.l.], v. 2, n. 1, 2020.

SILVA, Ana Cláudia Rodrigues; MATOS, Silvana; QUADROS, Marion. Economia Política do Zika: Realçando relações entre Estado e cidadão. Revista Anthropológicas, [S.l.], ano 21, v. 28, n. 1, p. 223-246, 2017.

TIME. Celina Turchi' by Tom Frieden: TIME 100. 2017. Disponível em: https://time.com/collection/2017-time-100/4742680/celina-turchi/. Acesso em: $1^{\circ}$ maio 2020 .

VALLE, Carlos Guilherme do. Identidades, doença e organização social: um estudo das pessoas vivendo com HIV e Aids. Horizontes Antropológicos, [S.l.], n. 17, p. 179-210. 2002

VALLE, Carlos Guilherme do. Doença, ativismo biossocial e cidadania terapêutica: a emergência da mobilização de pessoas com HTLV no Brasil - Illness, biosocial activism and therapeutic citizenship: the emergence of the mobilization of People with HTLV in Brazil. Vivência: Revista de Antropologia, [S.l.], v. 1, n. 41, 2013.

WATCHEL, Karen; CARTER, Alice S. Reaction to Diagnosis and Parenting Styles among Mothers of Young Children with ASDs. Autism, [S.l.], v. 12, n. 5, p. 575-594, 2008.

WHO - WORLD HEALTH ORGANIZATION. Director-General summarizes the outcome of the Emergency Committee regarding clusters of microcephaly and Guillain-Barré syndrome. 1 February 2016. Disponível em: https://www.who.int/emergencies/zika-virus-tmp/en/. Acesso em: $1^{\circ}$ maio 2020. 
Recebido em 16/09/2019

Aceito em 27/05/2020

\section{Luciana Lira}

Doutora em Antropologia pela Universidade Federal de Pernambuco, com pósdoc pelo Programa Nacional de Pós-Doutorado da Capes (PNPD - 2016-2019) no Projeto: “Etnografando Cuidados e Pensando Políticas de Saúde e Gestão de Serviços para Mulheres e Seus Filhos com distúrbios Neurológicos relacionados com o Zika Vírus em Pernambuco, Brasil". Pesquisadora do Núcleo Família, Gênero e Sexualidade - FAGES (UFPE). Tem se dedicado a pesquisas sobre diferentes temáticas a partir da relação entre gênero, saúde e corpo.

Endereço profissional: Faculdade Damas - FADIC. Av. Rui Barbosa, 1426-B, Graças, Recife, PE. CEP: 52.050-060.

E-mail:ludelira@gmail.com

\section{Helena Prado}

Desde 2017, vem desenvolvendo pesquisa sobre biopolíticas e uso de biotecnologias, em particular no que diz respeito às representações do corpo feminino e à vida reprodutiva e sexual no campo da saúde. Conduziu um trabalho de campo em vários centros urbanos do Brasil sobre as narrativas das mulheres e dos profissionais de reprodução humana após a epidemia do vírus Zika e a síndrome congênita associada. Iniciou em 2020 uma pesquisa em Lisboa sobre promotores de tecnologias de enhancement (cirurgia estética, entre outros), mercado transnacional do bem-estar e do turismo médico.

Endereço profissional: DynamE - Dynamiques Européennes UMR 7367, MISHA, 5 allée du Général Rouvillois, CS 50008, 67083, Strasbourg, Cedex.

E-mail: helenamprado@gmail.com 